\title{
Inhibition of migration and invasion by berberine via inactivation of PI3K/Akt and p38 in human retinoblastoma cell line
}

\author{
Yuwen Wang ${ }^{A, D, F}$, Jianshu Yuann ${ }^{B, D, F}$, Liangyan Yang ${ }^{B, D, F}$, Pengyun Wang ${ }^{B, D, F}$, Xiajun Wang $^{B, D, F}$, Yue $W^{C}{ }^{C, D, F}$, \\ Kan Chen ${ }^{C, D, F}$, Rong Ma ${ }^{C, D, F}$, Yike Zhong ${ }^{C, D, F}$, Xiaohong Guo ${ }^{B, F}$, Yan Gong ${ }^{B, F}$, Mengfang Gui ${ }^{C}, F$, Yaming Jin ${ }^{C, F}$ \\ Department of Ophthalmology, Ningbo Eye Hospital, China \\ A - research concept and design; $\mathrm{B}$ - collection and/or assembly of data; $\mathrm{C}$ - data analysis and interpretation; \\ $D$ - writing the article; $E$ - critical revision of the article; $F$ - final approval of the article
}

Address for correspondence

Yuwen Wang

E-mail: wangyuwen111@126.com

\section{Funding sources}

None declared

Conflict of interest

None declared

Received on January 16, 2017

Reviewed on February 26, 2017

Accepted on April 12, 2017
DOI

10.17219/acem/70418

\section{Copyright}

Copyright by Author(s)

This is an article distributed under the terms of the

Creative Commons Attribution Non-Commercial License

(http://creativecommons.org/licenses/by-nc-nd/4.0/)

\section{Abstract}

Background. As a clinically important natural isoquinoline alkaloid, berberine has been reported to possess various pharmacological effects.

Objectives. This study was aimed to investigate the effect of berberine on cell migration and invasion in human retinoblastoma $(\mathrm{Rb})$ cells.

Material and methods. The cytotoxicity of berberine was estimated by 3-(4,5-dimethylthiazol-2-yl)-2,5diphenyltetrazolium bromide (MTT) assay. After being stimulated with berberine under various concentrations, the cell migration and invasion were evaluated by transwell assay. Then, the expression levels of epithelial-mesenchymal transition (EMT) markers were determined by quantitative reverse transcription $P C R$ (qRT-PCR) and western blot analysis. Furthermore, the phosphorylation levels of protein kinase $B$ (Akt) and p38 were detected by western blot analysis. Finally, the effect of phosphatidylinositol-3-kinase (PI3K) and p38 inhibitors on cell migration and invasion was estimated by transwell assay. Untreated cells acted as control for all the experiments.

Results. The concentrations of berberine for further studies were controlled in a range of 0 to $100 \mu \mathrm{M}$. The cell migration and invasion were both suppressed by berberine in a dose-dependent manner compared to the control $(p<0.05$ or $p<0.001)$. Berberine remarkably down-regulated expression of $E$-cadherin and up-regulated expression of vimentin and a-SMA compared to the control ( $p<0.01$ or $p<0.001)$. Furthermore, the phosphorylation levels of Akt and p38 were both down-regulated by berberine in comparison to the control. Furthermore, the addition of berberine accompanied by LY294002 or SB203580 significantly suppressed cell migration and invasion compared to the addition of berberine alone $(p<0.05)$.

Conclusions. Berberine suppressed cell migration and invasion via inactivation of PI3K/Akt and p38.

Key words: berberine, invasion, epithelial-mesenchymal transition, phosphatidylinositol 3-kinase/protein kinase B/Akt, p38 


\section{Introduction}

Retinoblastoma $(\mathrm{Rb})$ is the most common eye tumor which arises in the retina and represents $2.5-4 \%$ of pediatric cancers. ${ }^{1}$ The etiology of $\mathrm{Rb}$ is the mutation of the $\mathrm{Rb}$ tumor-suppressor gene. ${ }^{2}$ As a cancer that occurs most often in children before the age of 5 years, Rb affects $2-5$ per million children in the USA and Europe. ${ }^{3}$ The most frequent clinical manifestations of $\mathrm{Rb}$ are leukocoria (white reflection in the pupil) and strabismus (macular involvement). ${ }^{4}$ Substantial therapies have been reported to control $\mathrm{Rb}$, such as enucleation, focal therapy, gene therapy, cryotherapy, transpupillary thermotherapy, chemotherapy, and radiotherapy. ${ }^{5-8}$ The therapies vary depending on the size of the tumor. Despite the good prognosis of $\mathrm{Rb}$, mortality induced by development of a $2^{\text {nd }}$ tumor remains high. Therefore, novel therapy should be further investigated.

Berberine is an isoquinoline alkaloid (Fig. 1A) isolated from the traditional Chinese medicine Coptis. ${ }^{9}$ Extensive research within the past decade proposes that berberine possesses a wide range of pharmacological activities, including anti-diabetic, anti-inflammatory, and anti-tumoral activity. ${ }^{10-13}$ Moreover, berberine has been reported to inhibit human colon cancer cell migration via down-regulation of integrin. ${ }^{14}$ Chou et al. have implied that berberine could induce cytotoxicity in breast cancer cells. ${ }^{15}$ Yip et al. illustrated that berberine induced apoptosis in liver cancer cells. ${ }^{16}$ A recent study suggests that berberine is a promising safe anti-cancer agent through affecting the mitochondria. ${ }^{17}$ To our knowledge, there is little study focus on the effect of berberine on $\mathrm{Rb}$. Thus, we are interested to know whether berberine can play an efficient role against $\mathrm{Rb}$.

The cell migration and invasion of cancer cells allow them to change position and make the neoplastic cells enter lymphatic and blood vessels for dissemination. After that, metastatic growth occurs in distant organs. ${ }^{18}$ As a consequence, the control of cancer cell migration and invasion is a substantial focus of cancer treatment. The present study was designed to investigate the effects of berberine on cell migration, invasion and epithelialmesenchymal transition (EMT) in human Rb Y-79 cells, which would make a contribution for the discovery of novel therapeutic methods. A previous study has demonstrated that phosphatidylinositol 3-kinase (PI3K)/Akt and p38 are involved in cell migration and invasion, thus we employed specific PI3K inhibitor 2-(4-morpholinyl)-8-phenyl-chromone (LY294002) and p38 inhibitor SB203580 to thoroughly investigate the underlying mechanism. ${ }^{19}$

\section{Material and methods}

\section{Cell culture}

The human Rb Y-79 cell line was purchased from American Type Culture Collection (ATCC, Manassas, USA). Cells were cultured in RPMI-1640 medium (Gbico, Grand Island, USA) supplemented with 10\% fetal bovine serum (FBS), $2 \mathrm{mM}$ L-glutamine, $1 \mathrm{mM}$ sodium pyruvate, $100 \mathrm{U} / \mathrm{mL}$ penicillin, and $100 \mathrm{U} / \mathrm{mL}$ streptomycin (Gbico, Rockville, USA). Cell cultures were maintained in an incubator with a humidified atmosphere of $5 \% \mathrm{CO}_{2}$ at $37^{\circ} \mathrm{C}$.

\section{Berberine preparation}

Berberine (purity $\geq 95 \%$, Sigma, St. Louis, USA) was dissolved in dimethyl sulfoxide (DMSO) and filtrated by $0.2 \mu \mathrm{m}$ disc filters (Millipore, Billerica, USA), resulting in appropriate amounts of stock solution (100 mM in DMSO). The stock solution of berberine was diluted with cultured medium to achieve the indicated concentrations. The final concentration of DMSO was less than $0.2 \%$.

\section{Cell viability assay}

To estimate the cytotoxicity of berberine, the cell viability of Rb cells was performed using the 3-(4,5-dimethylthiazol-2-yl)-2,5-diphenyltetrazolium bromide (MTT) assay in line with the standard method described above. ${ }^{20}$ Briefly, Rb cells were seeded onto a 96-well plate (Corning, Corning, USA) with a density of $4 \times 10^{3}$ cells $/ \mathrm{mL}$ for $24 \mathrm{~h}$. After that, the cells were treated with berberine under various concentrations $(0,5,10,20,40,80$ and $160 \mu \mathrm{M})$ for $24 \mathrm{~h}$ or $48 \mathrm{~h}$. Following removal of the medium and cell washing by phosphate buffer solution (PBS), $10 \mu \mathrm{L}$ of MTT solution ( $5 \mathrm{mg} / \mathrm{mL}$, Sigma, St. Louis, USA) was added to each well accompanied by incubation at $37^{\circ} \mathrm{C}$ for $4 \mathrm{~h}$. Then, $200 \mu \mathrm{L}$ of DMSO was added to solubilize the formazan. After measurement by a microplate reader (Bio-Rad, Hercules, USA) at $570 \mathrm{~nm}$, the cell viability was calculated by comparison with untreated cells.

\section{Migration and invasion assays}

Cell migration and invasion assays were both performed with Hanging Cell Culture-inserts (BD Biosciences, San Jose, USA) with pores of $8.0 \mu \mathrm{m}$ in 24-well plates (Corning, Corning, USA). Retinoblastoma cells were firstly stimulated with berberine under various concentrations and maintained for $24 \mathrm{~h}$. After that, cells were treated with trypsin and resuspended with a density of $1 \times 10^{5} / \mathrm{mL}$ in serum-free medium. When the lower chamber was filled with medium containing 10\% FBS, the cells were placed in the upper chamber. After culturing for $24 \mathrm{~h}$, the nonmigrated cells which stayed at the surface of the membrane were gently removed with a cotton-tipped swab. Cells that migrated across the filter as well as attached to the underside of the membrane were fixed with methanol and stained with $0.1 \%$ crystal violet. Finally, the stained cells were collected and counted under a light microscope (Olympus Optical Co. Ltd., Tokyo, Japan). Whether the inserted filter was pre-coated or not was the difference between the migration assay and invasion assay. In terms of the 
invasion assay, the filter was pre-coated with $200 \mu \mathrm{g} / \mathrm{mL}$ Matrigel (BD Biosciences, San Jose, USA). As for the migration assay, the filter was not coated with Matrigel.

\section{Quantitative reverse transcription of polymerase chain reaction}

According to the corresponding manufacturer's instructions, isolation of total RNA, reverse transcription of RNA and PCR reactions were performed with TRIzol (Invitrogen, Carlsbad, USA), GoScript ${ }^{\mathrm{TM}}$ Reverse Transcription System (Promega, Madison, USA) and Power SYBR Green PCR master mix (Applied Biosystems, Foster City, USA), respectively. Primers were designed and synthetized as shown in Table 1 (Sangon Biotech, Shanghai, China). The results were estimated with $2^{-\Delta \Delta C t}$ method and normalized to glyceraldehyde 3-phosphate dehydrogenase (GAPDH) for mRNAs. ${ }^{21}$

Table 1. Primers used in this study

\begin{tabular}{|c|c|}
\hline Gene & Primer sequence \\
\hline E-cadherin & $\begin{array}{l}\text { forward 5'- TTCTGCTGCTCTTGCTGTTT -3' } \\
\text { reverse 5'- TGGCTCAAGTCAAAGTCCTG -3' }\end{array}$ \\
\hline Vimentin & $\begin{array}{l}\text { forward 5'- GCCCTTAAAGGAACCAATGA -3' } \\
\text { reverse 5'- AGCTTCAACGGCAAAGTTCT -3' }\end{array}$ \\
\hline a-SMA & $\begin{array}{c}\text { forward 5'- AGGTAACGAGTCAGAGCTTTGGC -3' } \\
\text { reverse 5'- CTCTCTGTCCACCTTCCAGCAG -3' }\end{array}$ \\
\hline GAPDH & $\begin{array}{l}\text { forward 5'- CATCAATGGAAATCCCATCA -3' } \\
\text { reverse 5'- TTCTCCATGGTGGTGAAGAC -3' }\end{array}$ \\
\hline
\end{tabular}

a-SMA - a-smooth muscle actin; GAPDH - glyceraldehyde 3-phosphate dehydrogenase.

\section{Western blot analysis}

After lysing by RIPA buffer (Beyotime, Shanghai, China) and centrifuged at $4^{\circ} \mathrm{C}$, the protein in lysate was quantified using bicinchoninic acid (BCA) assay kit (Pierce, Rockford, USA). Fifty micrograms of protein was loaded and separated by sodium dodecyl sulfate polyacrylamide gel electrophoresis (SDS-PAGE). Then, the protein was transferred to polyvinylidene fluoride (PVDF) membranes (Millipore, Billerica, USA) and blocked with 5\% skim milk (Nestlé, Shuangcheng, China) in Tris-buffered saline with Tween 20
(TBST). Subsequently, the membranes carrying blots were incubated with primary antibodies against E-cadherin (ab1416), vimentin (ab8978), $\alpha$-smooth muscle actin ( $\alpha$-SMA, ab5694), $\beta$-actin (ab8226) (all from Abcam, Cambridge, UK), phosphorylated Akt (p-Akt, Ser473, 4060) and phosphorylated p38 (p-p38, 4511) (both from Cell Signaling, Beverly, USA) at $4^{\circ} \mathrm{C}$ overnight. After rinsing with TBST, the PVDF membranes were incubated with horseradish peroxidase (HRP)-conjugated secondary antibodies at $37^{\circ} \mathrm{C}$ for $1 \mathrm{~h}$. Protein bands were visualized utilizing the EasyBlot enhanced chemiluminescence (ECL) kit (Sangon, Shanghai, China) and LAS-3000 (Fuji Photo Film, Tokyo, Japan). The housekeeping gene was $\beta$-actin.

\section{Statistical analysis}

All experiments were repeated 3 times. The results were presented as the mean \pm standard deviation (SD) or the mean + SD. Statistical analysis was performed using GraphPad Prism 5 software (GraphPad, San Diego, USA). The p-values were calculated using the one-way analysis of variance (ANOVA) or Student's t-test. Significant differences were distinguished with $\mathrm{p}<0.05$.

\section{Results}

\section{Cytotoxicity of berberine on retinoblastoma cells}

Berberine is one kind of natural isoquinolyl-alkaloid which exist in a large number of medicinal materials. The molecular structure of berberine is shown in Fig. 1A. In order to examine the effect of berberine on cell viability of Rb cells, we employed MTT assay to analyze the cytotoxicity of berberine to Rb cells. In terms of berberine stimulation for $24 \mathrm{~h}$ or $48 \mathrm{~h}$, concentrations ranging from 0 to $100 \mu \mathrm{M}$ were suitable for further investigation (Fig. 1B). When the concentration of berberine was higher than $100 \mu \mathrm{M}$, the cell viability was too low to conduct other experiments. Thus, the concentrations of berberine for further studies were controlled in a range of 0 to $100 \mu \mathrm{M}$.
A<smiles>COc1ccc2cc3[n+](cc2c1OC)CCc1cc2c(cc1-3)OCO2</smiles>

Chemical structure of berberine (molecular weight $=371.8)$

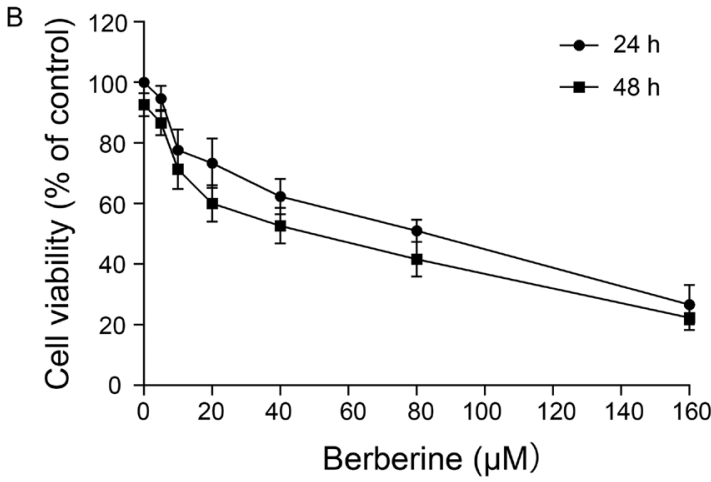

Fig. 1. The effect of berberine on the cell viability in human $\mathrm{Rb}$ cells

A - chemical structure of berberine; $B$ - retinobladtoma cells were treated with berberine under various concentrations $(0,20,40,60,80,100$, 120,140 and $160 \mu \mathrm{M}$ ) for $24 \mathrm{~h}$ or $48 \mathrm{~h}$. Thereafter, cell viability was determined by 3-(4,5-dimethylthiazol-2-yl)-2,5diphenyltetrazolium bromide (MTT) assay. The data presented was the mean of 3 independent experiments. Error bars indicate standard deviation (SD). 

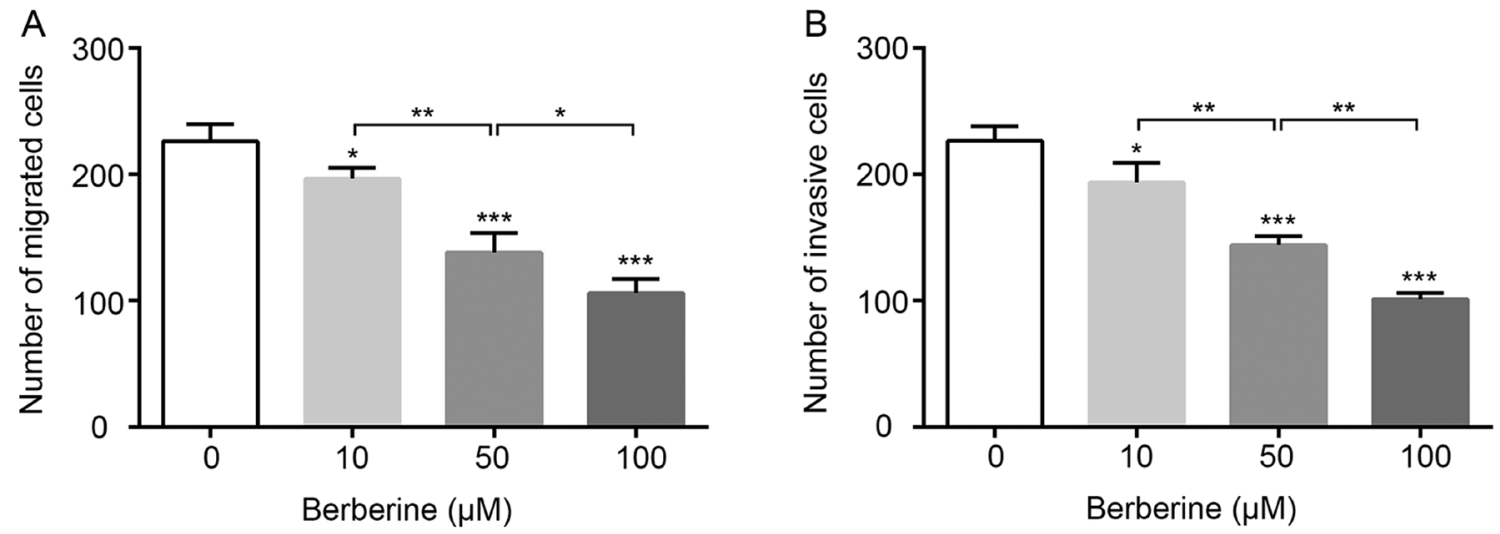

Fig. 2. The suppressive effect of berberine on cell migration and invasion in human Rb cells

Retinoblastoma cells were stimulated by berberine under 0, 10, 50 or $100 \mu \mathrm{M}$. After stimulation for $24 \mathrm{~h}$, the cell migration (A) and invasion (B) were both measured by transwell analysis. The data presented was the mean of 3 independent experiments. Error bars indicate standard deviation (SD). ${ }^{*} \mathrm{p}<0.05$; ${ }^{* *} \mathrm{p}<0.01 ;{ }^{* * *} \mathrm{p}<0.001$. The significance marked at the top of the columns refers to comparisons with the group treated with $0 \mu \mathrm{M}$ berberine.
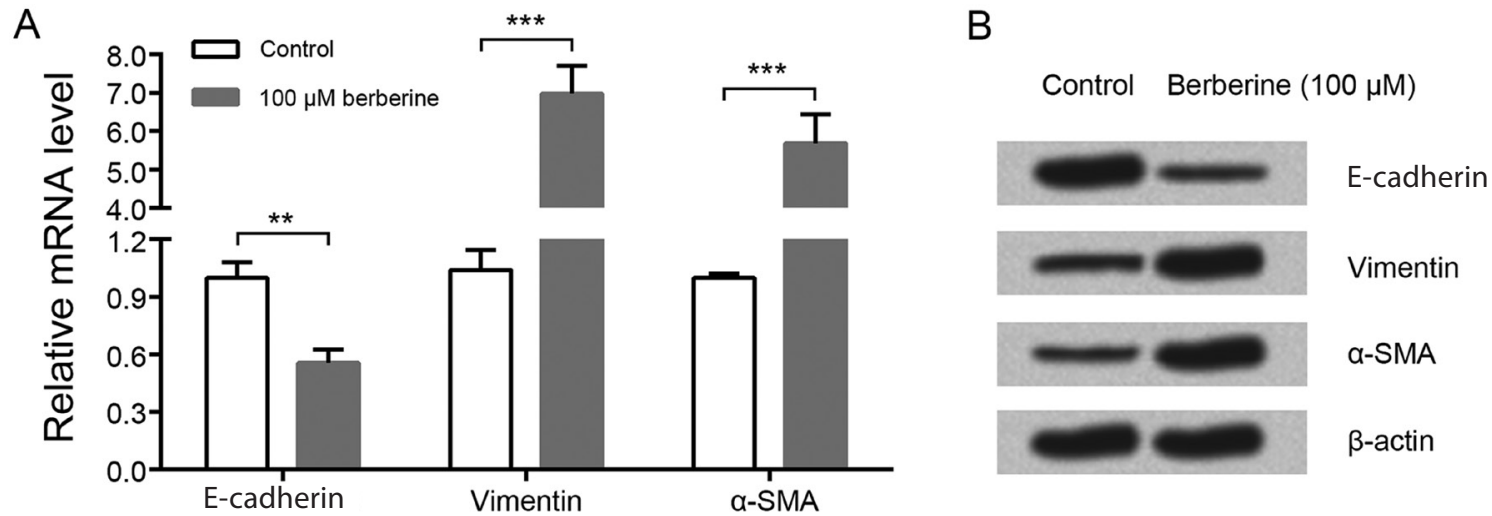

Fig. 3. The inhibitory effect of berberine on epithelial-mesenchymal transition (EMT) in human Rb cells

Retinoblastoma cells were stimulated with or without berberine $(100 \mu \mathrm{M})$. Cells treated without berberine acted as the control. After stimulation for $24 \mathrm{~h}$, the mRNA (A) and protein (B) levels of EMT markers were respectively estimated by quantitative reverse transcription PCR (qRT-PCR) and western blot analysis. The data presented was the mean of 3 independent experiments. Error bars indicate SD. ${ }^{* *} p<0.01 ;{ }^{* *} p<0.001 ; a-S M A-a-s m o o t h$ muscle actin.

\section{Berberine suppressed cell migration and invasion of retinoblastoma cells in a dose-dependent manner}

The cell migration and invasion assays were performed with berberine stimulation under various concentrations $(0,10,50$ and $100 \mu \mathrm{M})$. The cells without berberine treatment acted as a control group. In Fig. 2A, 2B, the cell migration and invasion of $\mathrm{Rb}$ cells were both suppressed by berberine under 10,50 and $100 \mu \mathrm{M}$ in comparison with controls $(\mathrm{p}<0.05$ or $\mathrm{p}<0.001)$. Further comparison between the cells treated with $50 \mu \mathrm{M}$ of berberine and $10 \mu \mathrm{M}$ of berberine $(\mathrm{p}<0.01)$ as well as $50 \mu \mathrm{M}$ of berberine and $100 \mu \mathrm{M}$ of berberine $(\mathrm{p}<0.05$ or $\mathrm{p}<0.01)$ implied that berberine suppressed cell migration and invasion in a dosedependent manner.

\section{Berberine inhibited epithelial to mesenchymal transition in retinoblastoma cells}

In view of the great importance of epithelial to mesenchymal transition (EMT) in the development of invasive cancer cells, we assessed the effect of berberine on EMT markers in Rb cells. The mRNA and protein levels of EMT markers were respectively estimated by qRT-PCR and western blot analysis. Retinoblastoma cells were treated with or without berberine $(100 \mu \mathrm{M})$ and cells treated without berberine acted as the control. As shown in Fig. 3A, berberine treatment significantly decreased E-cadherin mRNA levels and increased vimentin and $\alpha$-SMA mRNA levels compared to controls ( $\mathrm{p}<0.01$ or $\mathrm{p}<0.001)$. The effect of berberine on protein levels of $E$-cadherin, vimentin and $\alpha$-SMA was in accordance with mRNA levels (Fig. 3B). Thus, we drew the conclusion that berberine inhibited EMT in Rb cells. 


\section{Berberine suppressed cell migration and invasion via inactivation of PI3K/Akt and p38 in retinoblastoma cells}

The protein levels of p-Akt and p-p38 were evaluated by western blot analysis. Retinoblastoma cells were treated with or without berberine $(100 \mu \mathrm{M})$ and the cells treated without berberine acted as the control. In Fig. 4A, the protein levels of p-Akt and p-p38 were both down-regulated by berberine stimulation. Furthermore, Rb cells were stimulated with berberine $(100 \mu \mathrm{M})$ alone or accompanied with PI3K inhibitor LY294002 (10 $\mu$ M, Sigma, San Francisco, USA) or p38 inhibitor SB203580 (10 $\mu$ M, Sigma, St. Louis, USA). Cells treated without berberine acted as the control. In Fig. 4B, 4C, cell migration and invasion were remarkably inhibited by the addition of berberine compared to controls ( $p<0.01$ or $p<0.001$ ). Reasonably, co-stimulation of berberine with LY294002 or SB203580 markedly suppressed cell migration and invasion in comparison with stimulation with berberine alone $(\mathrm{p}<0.05)$. Taken together, we inferred that berberine suppressed cell migration and invasion through inactivation of PI3K/Akt and p38 in Rb cells.

\section{Discussion}

The prognosis of $\mathrm{Rb}$ alone is excellent in patients, with a cure rate of $95 \%$ in developed countries. Nonetheless, the existing therapies may enhance the risk of occurrence of secondary neoplasms. Hence, the development of novel non-mutagenic therapy is urgent for avoiding a $2^{\text {nd }}$ tumor. In the present study, we found that berberine significantly suppressed cell migration, invasion and EMT. Additionally, the phosphorylation level of Akt and p38 were both down-regulated by stimulation of berberine. Further studies on co-stimulation of berberine with a specific inhibitor of PI3K or p38 implied that berberine suppressed cell migration and invasion via suppression of PI3K/Akt and p38 phosphorylation.

High cell migration and invasion are two substantial characteristics for cancer cells. Numerous reports have illustrated the suppressive effect of berberine on cancer cells. Berberine suppressed migration and invasion of human SCC-4 tongue squamous cancer cells via inhibition of focal adhesion kinase (FAK), nuclear factor- $\kappa \mathrm{B}(\mathrm{NF}-\mathrm{\kappa} \mathrm{B})$, IкB kinase (IKK), urokinase-type plasminogen activator (u-PA), matrix metalloproteinase 2 (MMP-2), and MMP9. ${ }^{22}$ Berberine has also been reported to inhibit the migration and invasion of T24 bladder cancer cells through reducing the expression of heparanase. ${ }^{23}$ Moreover, berberine exerted suppressive effect on migration and invasion of hepatocellular carcinoma cells via altering the expression of plasminogen activator inhibitor-1 (PAI-1) and $\mathrm{u}-\mathrm{PA} .{ }^{24}$ The effect of berberine on the cell migration and invasion of $\mathrm{Rb}$ cells was consistent with the studies described above.

\section{A Control Berberine $(100 \mu \mathrm{M})$}
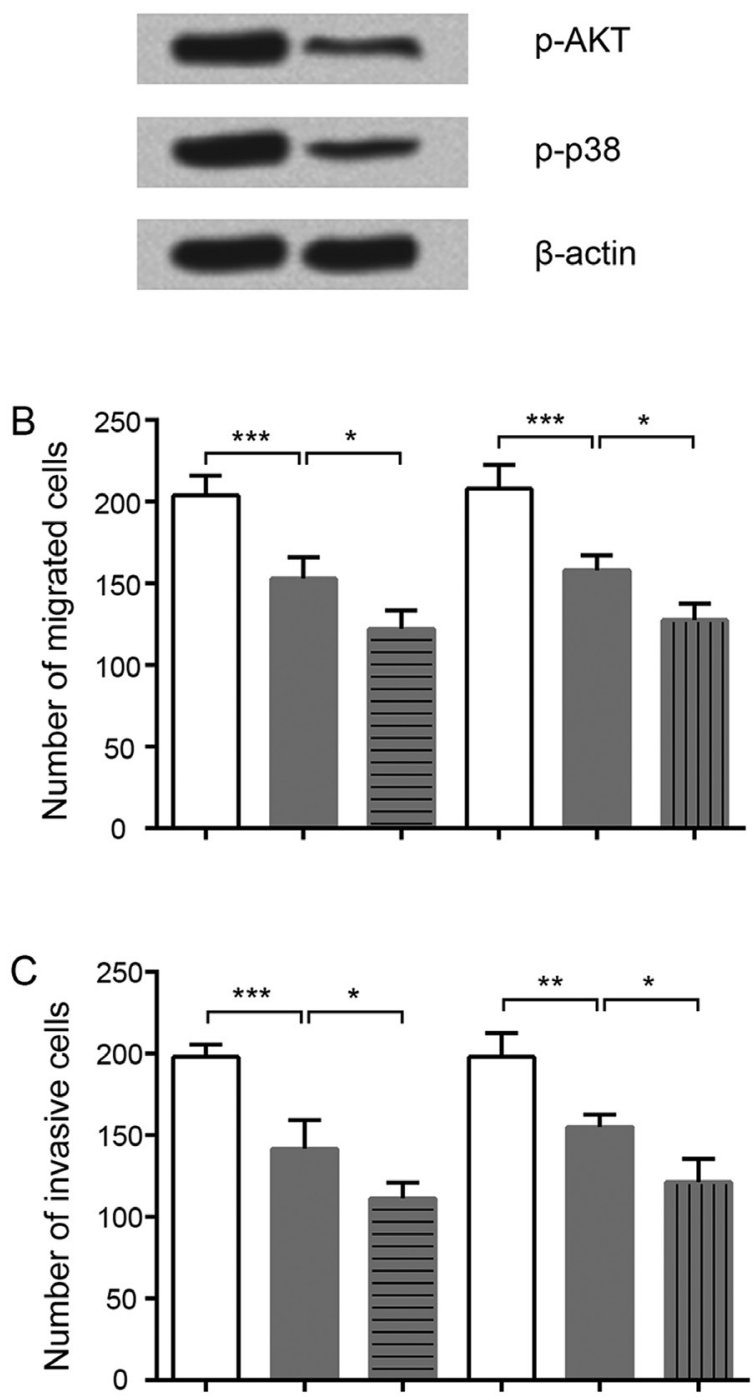

\section{Control \\ Berberine $(100 \mu \mathrm{M})$ \\ Berberine $+L Y$}

Fig. 4. The relationship between the suppressive effect of berberine on cell migration and invasion and inactivation of PI3K/Akt and p38

Cells were stimulated with or without berberine $(100 \mu \mathrm{M})$. After stimulation for $24 \mathrm{~h}$, the protein levels of $\mathrm{p}$-Akt and $\mathrm{p}$-p38 were estimated by western blot analysis (A). Furthermore, the cells were stimulated with berberine $(100 \mu \mathrm{M})$ alone or respectively co-stimulated with 2-(4-morpholinyl)-8-phenyl-chromone (LY294002, 10 HM) or SB203580 $(10 \mu M)$. After stimulation for $24 \mathrm{~h}$, the cell migration (B) and invasion (C) were evaluated by transwell analysis. Cells treated without berberine acted as the control. The data presented was the mean of 3 independent experiments. Error bars indicate SD. ${ }^{*} p<0.05$; ${ }^{* *} p<0.01$; ${ }^{* *} p<0.001$; LY - LY294002; SB - SB203580.

The complex metastasis of cancer consists of 5 continuous steps - proliferation, migration, invasion, adhesion, and angiogenesis. ${ }^{25}$ Epithelial to mesenchymal transition is characterized by the loss of cell-cell adhesion, which makes cells gain mesenchymal features and stem-like 
properties. The obvious effect of EMT on cells is improved migratory capacity and invasiveness, and reduced cell adhesion as well as resistance to cancer treatment. ${ }^{26} \mathrm{~A}$ previous study claimed that inhibition of the mTOR pathway attenuated the migration and invasion of gallbladder cancer via EMT inhibition. ${ }^{27}$ Recently, microRNA-133a was reported to suppress the migration and invasion of esophageal cancer cells by targeting the EMT regulator SOX4. ${ }^{28}$ In the present study, the results relevant to EMT markers suggested that berberine markedly inhibited EMT, which might be one reason for the suppressive effect of berberine on cell migration and invasion of Rb cells.

Protein Kinase B is a kind of serine-threonine kinase which acts as the primary downstream mediator of PI3K and participates in a large numbers of bioprocesses. ${ }^{29} \mathrm{P} 38$ is one of the mitogen activated protein kinases (MAPKs), which also has been reported to be involved in various cell processes. ${ }^{30} \mathrm{~A}$ previous study has claimed that a basic helix-loop-helix (bHLH) transcription factor (Twist), could increase migration and invasion of breast cancer cells via transcriptionally up-regulating Akt2. ${ }^{31}$ Heparanase has been reported to promote human gastric cancer cells migration and invasion by increasing phosphorylation level of p38. ${ }^{32}$ Specifically, Liu et al. have illustrated that inactivation of Akt or p38 induced down-regulation of both matrix metalloproteinase 2 (MMP-2) and MMP-9, leading to suppressive migration and invasion of human glioblastoma cells. ${ }^{33}$ In the present study, berberine stimulation significantly decreased protein expression levels of p-Akt and p-p38, implying that the inactivation of Akt and p38 might be another reason for the suppressive migration and invasion of Rb cells. Additionally, the comparison between cells treated with berberine alone and cells treated with berberine accompanied by the extra addition of PI3K inhibitor LY294002 or p38 inhibitor SB203580 seems to verify the inference. Furthermore, extensive investigations have suggested that EMT was induced by Akt or p38 signaling pathway. ${ }^{34-36}$ In a word, berberine suppressed cell migration and invasion through inactivation of PI3K/Akt and p38.

In summary, we are providing the first report for the suppressive effect of berberine on cell migration and invasion of human Rb cells in a dose-dependent manner. Furthermore, EMT was markedly inhibited by berberine. In addition, the suppressive effect of berberine on cell migration and invasion was due to the inactivation of PI3K/Akt and $\mathrm{p} 38$. Therefore, berberine may represent a new anticancer drug that can prevent metastasis of $\mathrm{Rb}$ and become a potential therapeutic agent.

\section{References}

1. Abramson DH, Schefler AC. Update on retinoblastoma. Retina. 2005;7:174-178.

2. Friend SH, Bernards R, Rogelj S, et al. A human DNA segment with properties of the gene that predisposes to retinoblastoma and osteosarcoma. Nature. 1986;323:187-206.

3. Parkin DM, Stiller CA, Draper GJ, Bieber CA. The international incidence of childhood cancer. Int J Cancer. 1988;42:511-520.
4. Phan IT, Stout T. Retinoblastoma presenting as strabismus and leukocoria. J Pediatrics. 2010;157:858-858.

5. Chawla B, Jain A, Azad R. Conservative treatment modalities in retinoblastoma. Ind J Ophthalmol. 2013;61:479-485.

6. Pandey AN. Retinoblastoma: An overview. Saudi J Ophthalmol. 2014; 28:310-315.

7. El Kettani A, Aderdour S, Daghouj G, et al. Retinoblastoma: Preliminary results of national treatment protocol at Casablanca university medical center. J Fr Ophtalmol. 2014;37:115-124.

8. Chang MW, Barr E, Seltzer J, et al. Cytostatic gene therapy for vascular proliferative disorders with a constitutively active form of the retinoblastoma gene product. Science. 1995;267:518-522.

9. Durairajan S, Liu LF, Lu JH, Chen LL. Berberine ameliorates $\beta$-amyloid pathology, gliosis, and cognitive impairment in an Alzheimer's disease transgenic mouse model. Neurobiol Aging. 2012;33:2903-2919.

10. Gulbahar O, Ozturk G, Erdem N, Kazandi AC, Kokuludag A. Antioxidant and anti-inflammatory activities of berberine in the treatment of diabetes mellitus: Evidence-based complementary and alternative medicine. eCAM. 2014;2014:71-80.

11. Chang W, Chen L, Hatch GM. Berberine as a therapy for type 2 diabetes and its complications: From mechanism of action to clinical studies. Biochem Cell Biol. 2014;1:1-8.

12. Cicero AF, Ertek S. Metabolic and cardiovascular effects of berberine: From preclinical evidences to clinical trial results. Clin Lipidol. 2015;4:553-563.

13. Xie J, Xu Y, Huang $X$, et al. Berberine-induced apoptosis in human breast cancer cells is mediated by reactive oxygen species generation and mitochondrial-related apoptotic pathway. Tumour Biol. 2015;36:1279-1288.

14. Park JJ, Seo SM, Kim EJ, et al. Berberine inhibits human colon cancer cell migration via AMP-activated protein kinase-mediated downregulation of integrin $\beta 1$ signaling. Biochem Biophys Res Commun. 2012;426:461-467.

15. Chou HC, Lu YC, Cheng CS, et al. Proteomic and redox-proteomic analysis of berberine-induced cytotoxicity in breast cancer cells. J Proteomics. 2012;75:3158-3176.

16. Yip NK, Ho WS. Berberine induces apoptosis via the mitochondrial pathway in liver cancer cells. Oncol Rep. 2013;30:1107-1112.

17. Diogo CV, Machado NG, Barbosa IA, Serafim TL, Burgeiro A, Oliveira PJ. Berberine as a promising safe anti-cancer agent - is there a role for mitochondria? Curr Drug Targets. 2011;12:850-859.

18. Chambers AF, Groom AC, Macdonald IC. Metastasis: Dissemination and growth of cancer cells in metastatic sites. Nat Rev Cancer. 2002;2: 563-572.

19. Chen PN, Hsieh YS, Chiou HL, Chu SC. Silibinin inhibits cell invasion through inactivation of both PI3K-Akt and MAPK signaling pathways. Chem Biol Interact. 2005;156:141-150.

20. Chen KS, Shi MD, Chien CS, Shih YW. Pinocembrin suppresses TGF- $\beta 1$ induced epithelial-mesenchymal transition and metastasis of human $Y-79$ retinoblastoma cells through inactivating av $\beta 3$ integrin/FAK/ p38a signaling pathway. Cell Biosci. 2014;4:1-13.

21. Schefe JH, Lehmann KE, Buschmann IR, et al. Quantitative real-time RT-PCR data analysis: Current concepts and the novel 'gene expression's CT difference' formula. J Mol Med. 2006;84:901-910.

22. Ho YT, Yang JS, Li TC, et al. Berberine suppresses in vitro migration and invasion of human SCC-4 tongue squamous cancer cells through the inhibitions of FAK, IKK, NF-KB, U-PA and MMP-2 and -9. Cancer Lett. 2009;279:155-162.

23. Yan L, Yan K, Kun W, et al. Berberine inhibits the migration and invasion of T24 bladder cancer cells via reducing the expression of heparanase. Tumour Biol. 2013;34:215-221.

24. Liu X, Ji Q, Ye N, et al. Berberine inhibits invasion and metastasis of colorectal cancer cells via COX-2/PGE2 mediated JAK2/STAT3 signaling pathway. PLOS One. 2015;10:e0123478.

25. Qi H, Xin L, Xu X, Ji X, Fan L. Epithelial-to-mesenchymal transition markers to predict response of berberine in suppressing lung cancer invasion and metastasis. J Trans/ Med. 2014;12:116-122.

26. Medici D, Muñoz-Cánoves P, Yang PC, Brunelli S. Mesenchymal transitions in development and disease. Stem Cells Int. 2016;2016:1-2.

27. Zong H, Yin B, Zhou H, Cai D, Ma B, Xiang Y. Inhibition of mTOR pathway attenuates migration and invasion of gallbladder cancer via EMT inhibition. Mol Biol Rep. 2014;41:4507-4512. 
28. Li S, Qin X, Li Y, et al. MiR-133a suppresses the migration and invasion of esophageal cancer cells by targeting the EMT regulator SOX4. Am J Transl Res. 2015;7:1390-1403.

29. Villegas-Comonfort S, Castillo-Sanchez R, Serna-Marquez N, Cortes Reynosa P, Salazar EP. Arachidonic acid promotes migration and invasion through a PI3K/Akt-dependent pathway in MDA-MB-231 breast cancer cells. Prostaglandins Leukot Essent Fatty Acids. 2014;90:169-177.

30. Coulthard LR, White DE, Jones DL, Mcdermott MF, Burchill SA. p38 MAPK: Stress responses from molecular mechanisms to therapeutics. Trends Mol Med. 2009;15:369-379.

31. Cheng GZ, Chan J, Wang Q, Zhang W, Sun CD, Wang LH. Twist transcriptionally up-regulates AKT2 in breast cancer cells leading to increased migration, invasion, and resistance to paclitaxel. Cancer Res. 2007;67:1979-1987.

32. Ma XM, Shen ZH, Liu ZY, et al. Heparanase promotes human gastric cancer cells migration and invasion by increasing Src and p38 phosphorylation expression. Int J Clin Exp Pathol. 2014;7:5609-5621.
33. Liu Y, Zheng J, Zhang Y, et al. Fucoxanthin activates apoptosis via inhibition of pi3k/akt/mtor pathway and suppresses invasion and migration by restriction of p38-MMP-2/9 pathway in human glioblastoma cells. Neurochem Res. 2016;41:2728-2751.

34. Li F, Yin X, Luo X, et al. Livin promotes progression of breast cancer through induction of epithelial-mesenchymal transition and activation of AKT signaling. Cell Signal. 2013;25:1413-1422.

35. Liu L, Dai Y, Chen J, et al. Maelstrom promotes hepatocellular carcinoma metastasis by inducing epithelial-mesenchymal transition by way of Akt/GSK-3ß/snail signaling. Hepatology. 2014;59:531-543.

36. Kolosova I, Nethery D, Kern JA. Role of Smad2/3 and p38 MAP kinase in TGF- $\beta 1$-induced epithelial-mesenchymal transition of pulmonary epithelial cells. J Cell Physiol. 2011;226:1248-1254. 